\title{
BMJ Open Quality Motivating Change: a grounded theory of how to achieve large-scale, sustained change, co-created with improvement organisations across the UK
}

\author{
Jenna P Breckenridge, ${ }^{\circ 1}$ Nicola Gray, ${ }^{2}$ Madalina Toma, ${ }^{2}$ Sue Ashmore, ${ }^{3}$ \\ Ruth Glassborow, ${ }^{4}$ Cameron Stark, ${ }^{5}$ Mary J Renfrew ${ }^{1}$
}

To cite: Breckenridge JP, Gray N, Toma M, et al. Motivating Change: a grounded theory of how to achieve large-scale, sustained change, co-created with improvement organisations across the UK. BMJ Open Quality 2019;8:e000553. doi:10.1136/ bmjoq-2018-000553

Received 16 0ctober 2018 Revised 5 May 2019 Accepted 26 May 2019
Check for updates

(C) Author(s) (or their employer(s)) 2019. Re-use permitted under CC BY-NC. No commercial re-use. See rights and permissions. Published by BMJ.

${ }^{1}$ School of Nursing and Health Sciences, University of Dundee, Dundee, UK

${ }^{2}$ Scottish Improvement Science Collaborating Centre, School of Nursing and Health Sciences, University of Dundee, Dundee, UK

${ }^{3}$ Baby Friendly Initiative, Unicef UK, London, UK

${ }^{4}$ Improvement Support and ihub, Healthcare Improvement

Scotland, Edinburgh, UK

${ }^{5}$ Public Health Medicine, NHS Highland, Inverness, UK

Correspondence to Dr Jenna P Breckenridge; j.breckenridge@dundee.ac.uk

\section{ABSTRACT}

Background Various theories provide guidance on implementing, sustaining and evaluating innovations within healthcare. There has been less attention given, however, to personal theories drawn from practice and the expertise of managers and front-line staff is a largely untapped resource. In this paper, we share learning from experienced improvement organisations to provide a conceptual level explanation of the conditions necessary to facilitate and sustain improvement at scale.

Methods Staff $(n=42)$ from three leading change organisations in the UK, spanning health, education and social care, took part in three consultation meetings with the aim of sharing knowledge about sustaining largescale change. This included one government organisation, one National Health Service Board and one large charity organisation. Using a participatory grounded theory approach, the workshops resulted in a co-created theory. Results The theory of Motivating Change describes the psychosocial-structural conditions for large-scale, sustained change from the perspectives of front-line staff. The theory posits that change is more likely to be sustained at scale if there is synergy between staff's perceived need and desire for improvement, and the extrinsic motivators for change. Witnessing effective change is motivating for staff and positive outcomes provide a convincing argument for the need to sustain improvement activity. As such, evidence of change becomes evidence for change. This is only possible when there is a flow of trust within organisations that capitalises on positive peer pressure and suppresses infectious negativity. When these conditions are in place, organisations can generate self-proliferating improvement. Conclusions The theory of Motivating Change has been co-created with staff and offers a useful explanation and guide for others involved in change work that capitalises on front-line expertise.

\section{INTRODUCTION}

Initiating and sustaining effective change in healthcare is a continuing challenge, with even the most successful improvements often being difficult to sustain or replicate in other contexts. ${ }^{1}$ Key figures in improvement science have emphasised the importance of learning from the psychological, social and structural processes influencing the implementation and maintenance of practice innovations. ${ }^{2}{ }^{3}$ They have called for researchers to look into the 'black box' of quality improvement to learn lessons from both successes and failures. ${ }^{4}$ Yet, a systematic review of 72 published studies of the impact of quality improvement collaboratives noted a marked absence of data about the conditions under which effective interventions were spread and sustained. ${ }^{4}$ Typically, improvement studies have been time-limited and small-scale, without rigorous evaluation of long-term outcomes ${ }^{5-8}$ or careful consideration of the scope and scale of change, the preparation prior to implementation, and the time, expertise and funding invested. ${ }^{9} 10$ Recognising the need for explicit guidance on implementing, sustaining and evaluating change at scale, various theories and frameworks have been developed to help guide this process, ${ }^{11}$ particularly in healthcare where there exist several notable examples: such as, the Institute for Healthcare Improvement (IHI) Framework for Spread. ${ }^{12}$ However, there is no 'magic bullet' for ensuring that the benefits of quality improvement initiatives endure $^{6}$ and key scholars have called for improvement scientists to draw on a range of cross-disciplinary knowledge in the pursuit of sustaining large-scale change. ${ }^{13}$

In addition to available theory, there is also considerable merit in listening to people who can share their lived expertise in successful sustained change ${ }^{5}$ or offer personal insights about the improvement evaporation effect, where new innovations are not maintained. ${ }^{14}$ There are various organisations actively operationalising large-scale improvement initiatives across the UK. Staff and managers within these organisations have their own personal theories of sustaining large-scale improvements, known in reflective practice discourse 
as re-theorising and reformulating, where professionals develop their own personal theories of practice drawn from experience. ${ }^{15}$ With a few exceptions, ${ }^{5} 16$ there has been little qualitative exploration of the personal experiences and expertise of managers and front-line staff, meaning that they are a largely untapped resource within the improvement science field. Ultimately, if we want to glimpse into the 'black box', it makes sense to speak to the people operating inside it and to value their experiential knowledge alongside theoretically and empirically derived academic frameworks.

\section{Context of the paper}

This paper presents the output of knowledge mobilisation activity as part of the work of the Scottish Improvement Science Collaborating Centre (SISCC). The SISCC is a Scotland-wide collaboration-involving universities, National Health Service (NHS) boards and partners in health, social care and the third sector-that aims to strengthen the research evidence base for how largescale, sustained change can be achieved and replicated in different contexts. SISCG works to a collaborative model, in which researchers work as equal partners with people who are directly involved in delivering improvement activity. The work presented in this paper originated in meetings between SISCC researchers and their partners to elicit advice about designing a programme of largescale improvement research. The consultation activity was initially a precursor in planning the SISCC research programme, but on realising the conceptual generality of the advice received, the researchers and partners agreed on the need to publish and share the lessons learnt more widely.

\section{METHODS}

Three full day consultation meetings were held with three different organisations during 2016 (table 1). The meetings involved a range of staff members from senior executives to front-line practitioners (42 attendees in total, with 12,15 and 15 attendees at each meeting, respectively). The consultation process was informed by classic grounded theory—a research method for generating theory directly from empirical experience. ${ }^{17}$ Grounded theory aims to develop practice-relevant theory directly from people with extensive experience, however, it typically continues to exist within a traditional research paradigm where researchers have ownership over the resulting theory. Instead, the work presented in this paper used a participatory approach, in which the process and the resulting theoretical product were co-created and co-owned in the context of knowledge mobilisation.

\section{Theory generation}

Each of the three full-day consultation meetings involved three rounds of progressively focused small group discussions in which participants were asked to reflect on the core activities involved in setting up, rolling out and sustaining improvements. At the start of the day we asked participants to work in groups to create their own personal theory of 'what works' when implementing and sustaining individual initiatives. We then asked groups to compare their different theories and to collectively identify similarities and differences in their understandings about 'what works' when sustaining different initiatives and contexts. Finally, groups engaged in discussion to critically compare their own theory about 'what works' in sustaining large-scale change with existing improvement models, theories and frameworks. By focussing first on the familiar, participants were able to consolidate their own personal theories, before progressing to a conceptual level discussion of general lessons for implementing large-scale sustainable change across different contexts.

Discussions were recorded on flip charts and additional notes were taken by three researchers. These were analysed by the first author using classic grounded theory processes in order to consolidate all of the data into one overarching theory. ${ }^{17}$ This involved the process of open coding to identify all possibilities in the data until a core category (motivating change) was identified. Thereafter, selective coding expounded the core category and related categories. This was followed by theoretical coding and memo-sorting to clarify the relationship between all components and arrive at an integrated theory. In these final stages of analysis, we agreed a unifying structure for the theory, which we organised according to psychosocial-structural conditions (described later). Theory development was discussed with a second researcher to enhance conceptual thinking and, in accordance with classic grounded theory, ${ }^{17}$ extant literature was consulted only after the theory was consolidated to support, extend and contextualise the new theory in the discussion section of this paper.

Following data analysis and consolidation of a first draft theory based on data from the consultation events, the partnership organisations provided the researchers with feedback according to grounded theory credibility criteria outlined by Glaser and Strauss.$^{17}$ Specifically, all three organisations responded positively to the final write-up of the theory, confirming: fit (the theory captures the workshop data and the social realities of their work); work (the theory offers a useful explanation); relevance (the theory has contextual relevance); and modifiability (there is potential for the theory to be transferred conceptually to different contexts). They also suggested refinements of the theory and these amendments were made iteratively until all authors were content that the theory presented a single voice that amalgamated the collective expertise of the three organisations.

\section{Patient involvement}

Patients were not directly involved in the design of this study. The focus of this project was accessing staff expertise; however, a future next step would be to seek patient and public input to develop the theory further and fully elucidate the key role they play in implementing, sustaining and evaluating large-scale change initiatives. 
Table 1 Participating partner organisations

\begin{tabular}{|c|c|c|}
\hline Name & Description & Scale, scope, duration of work programme \\
\hline Unicef UK & $\begin{array}{l}\text { We are a charity responsible for leading } \\
\text { large-scale, UK-wide improvement } \\
\text { initiatives in health and education. }\end{array}$ & $\begin{array}{l}\text { Reaching } 2 \text { million children through three work programmes: } \\
\text { Our Baby Friendly Initiative (introduced to the UK in 1995) has } \\
\text { spent over } 20 \text { years transforming care for babies, their mothers and } \\
\text { families. At the time of the consultation meetings, } 91 \% \text { of maternity } \\
\text { services were engaged with the Baby Friendly Initiative (60\% fully } \\
\text { accredited), along with } 85 \% \text { of health visiting services (58\% fully } \\
\text { accredited). } \\
\text { Our Rights Respecting Schools Award embeds child rights in daily } \\
\text { school life and gives children the best chance to lead happy, healthy } \\
\text { lives and to be responsible, active citizens. } 1.5 \text { million children go to } \\
\text { a Rights Respecting School, with more than } 4000 \text { schools working } \\
\text { towards the award. } \\
\text { Our Child Rights Partners programme works with local councils to } \\
\text { put children's rights at the heart of public services. Since November } \\
2013 \text {, we have trained nearly } 1000 \text { people working with vulnerable } \\
\text { children. In } 2017 \text { the programme was brought to scale with five new } \\
\text { local councils invited to join, with five additional councils brought in } \\
\text { year on year until } 2020 \text {. } \\
\text { For more information, see: https://www.unicef.org.uk/ }\end{array}$ \\
\hline
\end{tabular}

NHS Highland We are a Scottish health board facilitating improvement across integrated health and social care services.

$\begin{array}{ll}\text { Healthcare } & \begin{array}{l}\text { We are a national improvement } \\ \text { Improvement }\end{array} \\ \text { body commissioned by the Scottish } \\ \text { Scotland } & \begin{array}{l}\text { Government to support health and } \\ \text { social care organisations to improve } \\ \text { the health and well-being outcomes for } \\ \text { people in Scotland. }\end{array}\end{array}$

Our work covers $41 \%$ of the landmass of Scotland, with 24

populated islands and a population of 320000 residents. We have a revenue budget of $£ 695$ million and a staff headcount of 10000 . We span two Local Authority areas, 100 GP Practices (18 managed by NHS Highland), 25 hospitals and 15 directly managed care homes in the Highland Council area.

We have developed and implemented the Highland Quality Approach, which underpins the values, behaviour and ways of working across the health board. It is a board-wide, coordinated and concerted approach to providing person-centred care while at the same time eliminating waste, reducing harm and managing variation. Based on national strategy and guidance, which has been adapted where necessary to suit local circumstances, the Highland Quality Approach directs how we will put quality first to deliver better health, better care and better value.

For more information, see: http://www.nhshighland.scot.nhs.uk/ ABOUTUS/HQA/Pages/Welcome.aspx

We work with $21 \mathrm{NHS}$ Boards, 31 Integration Authorities, 32 Local Authorities and a wide and diverse range of housing, third and independent sector organisations. We provide a wide range of services: helping to empower people to participate in decisions about the design and delivery of services; supporting implementation of improvement; developing a robust evidence base for change; and assuring the public about the quality of their care. We have an annual budget of approximately $£ 30$ million, of which approximately a third is allocated to supporting improvement implementation.

Our Scottish Patient Safety Programme, a unique national initiative that aims to improve the safety and reliability of health and social care and reduce harm, whenever care is delivered, has been running successfully for 10 years. The Scottish Patient Safety Programme has received international recognition and is the first programme in the world to adopt a national approach to improving and patient safety within the health service. Through robust application of quality improvement methodology, the programme has resulted in significantly improved patient safety outcomes in a wide range of settings including: acute and primary care, mental health, maternity, neonatal, paediatric services, and medicine safety.

For more information, see: http://www. healthcareimprovementscotland.org/ 
Table 1 Continued

\begin{tabular}{lll}
\hline Name & Description & Scale, scope, duration of work programme
\end{tabular}

GP, General Practitioner; NHS, National Health Service.

A note on presentation and the structure of the theory

Unlike a traditional presentation of descriptive qualitative findings which might offer comparison of the participating organisations, this paper presents a single-voiced, co-created theory. The theoretical product is not a direct summary or replication of the data from the consultation meetings, but a conceptual amalgamation of the organisations' differing experiences and expertise. In keeping with classic grounded theory, the findings are written in the present tense using quotations sparingly and only as necessary to elucidate concepts. This is because theory should be organised around concepts-abstract of people, places and times- that are derived from data, rather than the data itself. ${ }^{17}$ The theory that follows is therefore not presented as an undisputed fact, but as a plausible and modifiable hypothesis about the key elements for creating sustainable large-scale improvement derived from the collective expertise of participants in the partner organisations. It represents a shared understanding agreed between all participants to present a simple, well-defined and well-integrated explanation.

As described earlier, the theory of Motivating Change is organised around the psychosocial-structural conditions for large-scale sustained improvement. By 'conditions', we are referring to the circumstances and factors that have an influence on or determine the outcome of improvement work. In the theory, these are grouped under three sets of conditions: psychological, social and structural. We define psychological conditions as relating to the human mind and to how people within organisations think and feel about improvement. Sustained improvement is similarly influenced by social conditions, which we define as the relationships between individuals within organisations and the wider organisational culture. Finally, structural conditions relate to the systems, resources, management structures and physical environments that constitute organisations.

\section{THE THEORY OF MOTIVATING CHANGE}

The central premise of the theory of Motivating Change is that organisations must create the right psychosocial-structural conditions for successful, large-scale sustained change. This means that there must be individual motivation to act (psychological conditions), collective support for action (social conditions), and structures that create capacity, capability and opportunity for action (structural conditions). A main concern for large-scale change organisations is embedding improvement that lasts. Rather than just implementing and sustaining one change-for example, a single initiative or specific project-the goal is to create long-term improvement cultures where positive attitudes towards improvement are generated and sustained. When staff

Table 2 Motivators for change

\begin{tabular}{|c|c|}
\hline Intrinsic motivator & Description \\
\hline Values & $\begin{array}{l}\text { To appeal to intrinsic motivations, a change must enable individual values (eg, person-centredness) to } \\
\text { be actualised. }\end{array}$ \\
\hline Extrinsic motivator & Description \\
\hline Bigger purpose & $\begin{array}{l}\text { There is moral imperative to make changes that improve outcomes and meet people's needs, often } \\
\text { illuminated through a human rights lens for example, upholding individuals' rights to education or } \\
\text { health. }\end{array}$ \\
\hline Government mandate & $\begin{array}{l}\text { Policy provides the external authority for change and sets the criteria for success, usually through } \\
\text { setting government-defined goals and targets. }\end{array}$ \\
\hline Societal pressure & $\begin{array}{l}\text { Societal pressure comes from the public and is intensified by the media, often in relation to emotive } \\
\text { topics, who call on organisations to respond to 'big issues' such as neglect, unsafe practice or } \\
\text { inequitable care provision }\end{array}$ \\
\hline Research evidence & $\begin{array}{l}\text { Empirical research feeds into the policy and guidelines that stimulate improvement activity. Research } \\
\text { evidence can motivate the need for change and directly inform how and what change is implemented. } \\
\text { Research evidence can minimise the potential for adverse consequences and poorly thought-out } \\
\text { change. }\end{array}$ \\
\hline
\end{tabular}


within organisations are actively seeking, enacting and maintaining improvement work, improvement becomes self-proliferating. The theory of Motivating Change posits that this is the lynchpin of successful, sustained change. Seeing evidence of successful change inspires front-line staff to seek out opportunities for improvement in the future and, in turn, effects a fundamental transformation in the intrinsic motivators shaping their attitudes and behaviours. When motivation spreads from one individual to another, there can be a collective cultural shift to a workforce with a desire and ability to see and act on improvement opportunities. And all of this can only be achieved in the presence of supportive structural conditions.

We now describe each of the psychosocial-structural conditions for sustained change at scale. We expand on the importance of these conditions and how they are created and sustained. We also provide case examples from each of the participating organisations; one example to illustrate each of the psychosocial-structural conditions.

\section{The psychological conditions for sustained large-scale change: internalised motivation}

Individual motivation for change is an important psychological condition that influences whether organisations achieve self-proliferating improvement. The different intrinsic and extrinsic motivations for change are summarised in table 2.

To harness individual motivation as a driving force for change, organisations can capitalise on the intrinsic motivations of staff and service users who are already committed to improvement. Inevitably, however, there will be varying degrees of motivation for change within any organisation and, often, change is instigated by external drivers. In this case, the extent to which externally motivated change aligns with staff's intrinsic values will determine how much perceived worth they attach to any given improvement activity. When government or organisational perceptions of a problem and solution differ significantly from the values of those delivering and using a service, it is less likely to motivate change. We define this as a 'policy-practice paradox', whereby competing internal and external priorities may prohibit progress towards improvement. For example, government-defined targets that are not considered relevant or necessary in localised areas can undermine motivation for change and turn staff and service users into passive resisters, rather than proactive change agents.

To reconcile this paradox, the theory of Motivating Change suggests that organisations must work to narrow the gap between the external drivers of change and the intrinsic motivators of staff at a local level. For this to happen, there must be (A) Convincing evidence that change is needed. (B) A continual process of turning evidence of change into evidence for change. In this way, organisations can support staff and service users to internalise the extrinsic motivators for change.
Provide evidence for change (show that change is needed)

For individuals who do not see the need for improvement, extrinsic motivators-such as research evidence or service user feedback — can be powerful in changing their minds. However, this is only effective when the external drivers for change align with individuals' intrinsic values. Certain extrinsic motivators are easier to reconcile with intrinsic motivations, for instance, a bigger purpose that advocates change as the 'right thing to do' feeds directly into the intrinsic motivations underpinning the work of many front-line staff. Similarly, service user voice is a powerful motivator for practitioners who intrinsically value person-centred care. As such, organisations must consider appealing to these intrinsic motivations when they select and use evidence as a rationale for change.

\section{Turn evidence of change into evidence for change (show that change is working)}

Seeing evidence that change is working is motivating. Positive outcomes provide a convincing argument for the need to sustain improvement activity. We conceptualise this as evidence of change becoming evidence for change; where external evidence becomes internalised as motivation for improvement. For this to happen, organisations must show that change is working in a way that appeals to different stakeholders in the change process. Data that work to convince front-line staff (eg, service user feedback) may not necessarily convince policy makers. Therefore, astute data collection and sharing data in a way that engages different audiences is key to turning evidence of change into evidence for change. Conversely, when no outcome data are collected or shared at all, this is highly demotivating, as the cycle of turning evidence of change into evidence for change is disrupted, since there is no reinforcement of change having a positive effect.

Table 3 provides a practical example from Unicef UK to illustrate how to motivate change by creating the right psychological conditions.

\section{The social conditions for sustained large-scale change: a flow of trust}

A critical social condition for sustained change at scale is trust. There must be trust between front-line staff, leaders and stakeholders who share a desire for change and a belief that the proposed improvements will be effective. In this way, motivation for change spreads through a flow of trust within an organisation. Although they are important, the internalised motivations of one individual cannot drive whole-scale sustained improvement alone. Rather, motivation for change needs to be collectively internalised, turning an external vision of change into a shared commitment across an organisation. The concepts of sustainability and spread commonly referred to in the improvement field therefore should relate to a particular innovation, and to spreading and sustaining motivation. Only in the right social conditions can motivations for change be internalised and enacted, enabled through a flow of trust that is influenced by: leadership, positive 
Table 3 Illustrating the psychological conditions for motivating change-a case example from Unicef UK

\section{What was the change?}

The Baby Friendly Initiative (BFI) is a set of best practice standards and the BFI award is a nationally recognised mark of quality care in maternity and health visiting services. Services implement the standards in stages over a number of years and at each stage they are externally assessed by Unicef UK. When they pass all stages, services are accredited and can ultimately go on to a Gold Award for the permanent embedding of BFI standards. Although services will have already been doing BFI, the requirements for the Gold Award are a significant step up. This requires considerable changes to the leadership, culture and systems within a service to enable BFI to be maintained in the long term.

\section{How did we motivate staff by providing a convincing argument for change?}

There was already convincing evidence of the impact of BFI in the service so far, particularly on breastfeeding initiation. This in itself provided a convincing rationale for putting in the hard work to make BFI sustainable.

A survey of staff at the outset of the process assessed how staff felt about the culture within the service in relation to BFI, including how valued it was and the opportunities to improve care. This helped to convince staff that their concerns and priorities were listened to and would inform the change process.

Parents were asked to make specific suggestions for improving the service they received. This increased staff motivation for change because they could see the direct link with improving the experiences and outcomes of mothers, babies and families. It also convinced staff that the change process would take account of the needs of service users right from the outset.

\section{How did we motivate staff by turning evidence of change into evidence for change?}

Ongoing service user feedback was collected virtually (via websites and social media) and via audit data where parents were asked directly for feedback about the impact of BFI on their direct care and outcomes. This helped to convince staff and managers of the difference the standards were making to the experiences of mothers, babies and their families and the need to sustain BFI.

peer pressure, infectious negativity and constructive resistance.

\section{Leadership}

Leaders establish a flow of trust through recognition and reward; turning evidence of change and into evidence for change. Effective leaders create positive energy from negative results by sharing learning to motivate the pursuit of improvement. By understanding what motivates individuals already committed to improvement, leaders can build these motivations in others and model these attributes. Leaders are, themselves, evidence of change; seeing front-line staff move on to become improvement leaders spreads capability, and spreads motivation through positive peer pressure.

\section{Positive peer pressure}

Positive peer pressure is a healthy competitiveness whereby the outward display of intrinsic motivation for change in one individual, becomes an extrinsic motivator for another. It enables evidence of change in one area to become evidence for change in another. Individuals (whether staff or service users) with existing strong intrinsic motivation can spread this through their relationships with others around them. People involved in successful improvement projects may be relocated to help operationalise improvements in other areas, both to spread capacity and exemplify motivated attitudes towards change. Front-line staff may be more willing to listen to a service user or a peer than to a manager or external organisation. For positive peer pressure to help scale up sustainable change, however, it must be founded on willingness to share best practice rather than a perverse desire to compete for resources and reward.

\section{Infectious negativity}

Counter to positive peer pressure, negativity can spread within an organisation, undermining intrinsic motivations for change. People may be resistant to change for various reasons and, if these go unacknowledged, can result in an apathy that hinders improvement. Infectious negativity may be more likely to occur when there is little attempt in the change process to narrow the gap between the extrinsic drivers of change and individuals' intrinsic values and local priorities. Infectious negativity can also spread when changes are not easy to measure or when the results are not as promising as hoped. When there is no convincing data that change is working, it is difficult to see evidence of change turn into evidence for change, fuelling apathy. In these circumstances, the presence of infectious negativity should prompt leaders to stop, reassess and seek ways of harnessing opposing views constructively (as described next). Of course, leaders are not immune from infectious negativity themselves, which may compromise their ability to model positive motivations. 
Constructive resistance

As opposed to unchecked infectious negativity, harnessing constructive resistance is important in designing, implementing and sustaining changes that are feasible and meaningful in practice. Listening to opposing views can help to improve the change intervention and enable critically minded staff to feel appreciated rather than disenfranchised. Moreover, providing individuals with the opportunity to voice and work through concerns about a change can be an important part of the psychological process of adjusting to that change.

Table 4 provides a practical example from Healthcare Improvement Scotland to illustrate how to motivate change by creating the right social conditions.

The structural conditions for sustained large-scale change Internalising the motivation for change and spreading motivation through a flow of trust is contingent on

Table 4 Illustrating the social conditions for motivating change-a case example from Healthcare Improvement Scotland

\section{What change was implemented?}

The Scottish Patient Safety Programme for Mental Health (SPSP-MH) aims to systematically reduce harm experienced by people using mental health services in Scotland by empowering staff to work with service users and carers to identify opportunities for improvement, test and implement interventions and spread successful changes in their area.

\section{How did we use leadership to create a flow of trust between stakeholders?}

We used a systematic improvement approach and codesigned the programme with all key stakeholders including clinical leaders, service users, carers, inpatient ward staff and service managers. The programme leadership built in mechanisms for ongoing adaptation in response to both quantitative data and qualitative feedback from clinicians, practitioners, service users and carers about what was and was not working.

A small national team supported the implementation of SPSP-MH, which included a part-time psychiatrist in recognition of the importance of engaging clinical leadership. Close links were also established with the national mental health nursing network, in recognition of the vital role of mental health nurses. SPSP-MH also had strong political and leadership support, with regular input from politicians and senior leaders across the healthcare system in face-to-face learning sessions.

SPSP-MH had a strong focus on engaging service users and carers from the start. Their involvement in the design of the programme included the development of a Patient Safety Climate Tool, which helps wards, units and boards collect qualitative and quantitative data about what needs to be changed and what is working well from the perspective of those receiving care. This helped to build trust with patients, staff, carers and others.

\section{How did we deal with infectious negativity?}

We stayed alert to the possibility of infectious negativity and put in efforts from the start to prevent this. We did this by viewing any potential negativity as a critical message from the system that we should listen to and use constructively (as described in the next box).

\section{Who were the key stakeholders?}

SPSP-MH is part of the Scottish Patient Safety Programme initiated by the Scottish Government to reduce harm in acute psychiatric inpatient wards. The programme was designed nationally with input from service user and carer representatives, inpatient ward staff, clinical leaders and service managers. Although this was a national programme, participation was voluntary (services could choose whether to get involved). All $12 \mathrm{NHS}$ Boards that had acute psychiatric inpatient units engaged from the beginning.

\section{How did positive peer pressure shape motivation for change?}

The positive impact already seen in the wider SPSP in acute hospitals created a context where mental health services were keen to join an already successful initiative.

We brought staff and leaders from the NHS Boards together on a regular basis (face to face or via webinar) to share learning about what was and was not working and to enable frontline staff to share their successes and challenges. This peerlearning network was critical for success and created a genuine sense that those delivering it are directly shaping its ongoing development.

Data, evidence and expert opinion (from both health professionals and people with experience of acute mental health issues) were combined to produce driver diagrams which outlined which interventions were most likely to reduce harm at a ward level.

We co-designed with stakeholders a standard set of outcome measures, the majority of which were not routinely collected prior to SPSP-MH. Making the current harm in the system more visible through measuring and reporting it fostered the will for change. The use of a consistent set of outcome measures also meant that we had data to identify where impact was happening (and where it was not). Initially the emphasis was on whether individual wards were improving against their own baselines. However, over time, comparative data were also used to support learning and motivation.

We have also developed a strong social media presence, with over 2700 followers on twitter @SPSP_MH to date.

\section{How did we harness constructive resistance?}

Significant concerns were raised in the initial design of SPSP$\mathrm{MH}$ by some clinicians and service users. They worried that it could result in an overly cautious approach to risk that would impact negatively on individuals' recovery. We addressed positive risk-taking directly and also developed 'balancing measures' to monitor any unintended consequences on positive risk-taking that is, average length of stay and levels of one-toone observation. 
specific structural conditions. These structures relate to the physical environment, finance, incentives, time and methodology.

\section{Physical environment}

Visual cueing in the physical environment (eg, achievement boards), which overtly displays evidence of improvement, fuels positive peer pressure and supports turning evidence of change into evidence for change.

\section{Finance}

Financial resource is often under the control of policy and organisational budgets rather than local areas. However, when financial savings from improvement activity are used directly to sustain the effort or to fund a future project in the same area, this is more motivating than seeing the resource redirected elsewhere in the system. This amplifies the potential for evidence of change to become evidence for change.

\section{Incentives}

Incentives such as accreditation or awards feed into positive peer pressure. However, where there is disconnect between the incentive (for instance, reaching a government-defined target) and the values and perceived need for change at a local level, these are unlikely to motivate change. Incentives may also have a perverse effect, where teams only 'up their game' at assessment time. This is more likely when the incentive does not appeal to staff's intrinsic motivation, that is, when there is a policy-practice paradox.

Table 5 Illustrating the structural conditions for motivating change-a case example from NHS Highland

\section{What change did we implement?}

NHS Highland introduced a weekly review of financial and performance information in a series of wards and teams, using information from the previous week, and leveraging this to produce change. Teams picked priorities, based on data from their own areas.

\section{What financial resource was available?}

Staff could see the expenditure on their service, using contemporaneous data. This made it easier to link actions to costs. There was no direct incentive for staff to reduce costs, but by increasing efficiency, they could offer their service to more patients. In the pilot ward, a respiratory service, they an improvement in quality of care. Staff found the line of sight between information, improvement and capacity motivating. reduced the number of 'off service' patients, and so focused on

\section{How did we use the physical environment to motivate} change?

We created a 'box score' showing metrics in five areas (safety, quality, patient experience, staff satisfaction, finance). These are displayed in a shared team area and a weekly huddle is held in front of the board. The linked improvement projects are shown on the same board, with their own metrics. Teams can see how their data align to their chosen priorities and current improvement projects.

\section{How did we use incentives?}

The incentives were more direct control of the team's own services, and ability to offer improved services. There were no financial rewards for staff. The focus on quality matched the intrinsic motivators of the majority of healthcare staff, who seemed to find work on quality more motivating than work on finance alone. Using a range of measures across staff and patient experience, quality and safety as well as finance reassured staff that money was not being considered to the exclusion of service quality. There was local recognition for the pilot services, but later services taking up the work were doing it as part of a roll-out plan, and this does not appear to have reduced the impact of the approach.

\section{What was the impact of timing?}

\section{How did our methodology support change?}

Staff routinely undertake quality improvement activities in their own areas, so there was no additional time devoted to projects, although there was increased alignment with team priorities, and therefore greater impact. Weekly huddles lasted only $30 \mathrm{~min}$. The original pilot was in an area that had already conducted a Rapid Process Improvement Workshop (RPIW), and so had experience of Quality Improvement work at a larger scale. They had also standardised processes to some extent, so were a good starting place.

Later teams were selected because of their place in linked value streams, and then of geographical location, allowing a local QI Collaborative approach. They did not all have previous experience of QI work, but the opportunity to work at the same time as neighbouring teams was successful and motivating.
The methods were overtly Lean, using Lean Accounting, but with regular use of the IHI Model for Improvement. Staff from the Institute of Healthcare Improvement in USA offered telephone coaching, which helped staff to be reassured that there was no conflict between improvement approaches. We provided local coaches to work with teams for around 2 hours a week, who were trained in Lean methods, and familiar with the Model for Improvement.

Several teams had already taken part in RPIWs, and/or had staff who had undertaken the Intermediate Highland Quality Approach training, which is intended to support team leaders to coach improvement work in their own team. The existing experience was therefore a good fit. The previous exposure to QI methods seemed to be helpful to teams, and coaching helped to articulate the links between methods and approaches, to reduce potential confusion. 
Time

Time relates both to the time for improvement (setting aside dedicated time and freeing up time in the schedules of busy practitioners) and the timing of improvement (ensuring the structural conditions are in place before initiating change). Although this can be carefully planned, there will always be an element of opportunism.

\section{Methodology}

An agreed process of change-whether locally designed or drawing on existing models such as the lean approach ${ }^{18}$ or the IHI Model of Improvement ${ }^{19}$ — can scaffold the improvement process. Consistent use of methodology can build and consolidate a flow of trust by promoting a shared language and vision. However, if the rigidity of the methodology does not allow staff to feel sufficiently autonomous and self-motivated, or service users to feel listened to and valued, it can also have a negative effect on sustained motivation.

Table 5 provides a practical example from NHS Highland to illustrate how to motivate change by creating the right structural conditions.

\section{Hypotheses}

The key propositions of the theory of Motivating Change (box 1) provide hypotheses for future research and can help in planning and monitoring large-scale change.

To support the application of the theory of Motivating Change in planning and evaluating future large-scale, sustainable change projects we have operationalised these concepts into a practical framework (table 6). The framework could be used to plan the implementation and scale-up of a change or could be used retrospectively to reflect on the conditions responsible for either the success or failure of the change. There are prompt questions to facilitate the application of each concept in the theory.

\section{DISCUSSION}

Motivating Change describes the psychosocial-structural conditions for sustained, large-scale change. It contributes to an international landscape of existing models for implementing and sustaining innovations-for example, Normalisation Process Theory ${ }^{20}$ and the NHS Sustainability Model $^{21}$ _by confirming the importance of context, collective action, cognitive participation, leadership, attitudes and organisational fit. However, by emphasising the centrality of motivation and describing the conditions for sustained change, rather than the process through which this is achieved, the theory of Motivating Change makes some additional useful contributions. Indeed, a systematic review of quality improvement models concluded that the specific model of improvement used is less important in determining successful sustained change than the conditions under which it is implemented. ${ }^{11}$ By highlighting the importance of personal motivations, Motivating Change challenges predominant discourses which privilege structural processes and workforce characteristics over individual and local contexts. Ultimately, when people are conceptualised
Box 1 : Propositions of the theory of Motivating Change

\section{Primary proposition:}

Turning evidence of change into evidence for change, within the context of a flow of trust and supporting structures, internalises extrinsic motivators and creates the right psychosocial-structural conditions for large-scale sustained change, transforming individuals and organisations into self-proliferating improvers.

\section{Subpropositions:}

Sustained change at scale requires organisations to be self-improving. Self-proliferating improvement is dependent on a combination of psychosocial-structural factors: the individual motivation to act, a collective motivation for action, and structures that create the capacity and opportunity for motivations to be enacted.

The closer the alignment between extrinsic and intrinsic motivators for change, the more likely it is that change will be implemented and sustained.

Turning evidence of change into evidence for change helps staff to internalise extrinsic motivators and redresses any potential policypractice paradox.

Developing and sustaining collective motivation for action is dependent on a flow of trust across the organisation that is mediated by leadership and positive peer pressure.

Leadership requires both the technical skills of leading improvement, and the relational skills required to create a positive flow of trust and facilitate the internalisation of extrinsic motivators.

In a culture of positive peer pressure, the outward display of intrinsic motivation for change in one individual becomes an extrinsic motivator for another.

Infectious negativity, catalysed by an unredressed policy-practice paradox, undermines the sustainability of improvement. Harnessing constructive resistance helps to design, implement and sustain changes that are relevant, feasible and meaningful in practice. Internalising the motivation for change and spreading motivation through a flow of trust is contingent upon specific structural conditions (physical environment, finance, incentives, time, methodology) that either facilitate or hinder successful improvement work.

as 'human factors', there is a risk that they are perceived simply as barriers or facilitators to the change process rather than as active agents. This can result in overly prescriptive, process-driven approaches that disengage rather than include staff and service users. ${ }^{22}$ Thus, Motivating Change contends that people should not be conceptualised as mere incidental factors along the way, but as the very key to establishing lasting improvement.

According to Self-Determination Theory, ${ }^{23}$ intrinsic motivation requires individuals to experience feelings of: autonomy (being able to act according to our values); competence (confidence that we can act in the way we want); and relatedness (connected to others through our actions and choices). For change to be self-determined, individuals must feel able to actualise these three senses regardless of whether the original driver for change is external or not. ${ }^{23}$ The theory of Motivating Change describes how extrinsic motivators become internalised in the context of quality improvement and identifies opportunities for enabling individuals to experience all three senses even when change is externally 
Table 6 The Motivating Change framework

What is the innovation or change being made?

Briefly describe the change

Who are the key stakeholders?

Briefly describe who is involved. Who is involved in leading the change? Who is affected by it?

The psychological conditions for motivating change

Is there a policy-practice paradox? What is it?

Is the change externally imposed? What disconnect exists, if any, between the proposed change and the perceived need in the local context? Is there a disconnect between the proposed change and staff's intrinsic values?

$\begin{array}{ll}\text { How will you motivate people by providing a convincing } & \text { How will you motivate people by convincing them that the change is } \\ \text { argument for change? } & \text { working? }\end{array} \begin{array}{ll}\text { What evidence can we use to convince them that the change is } & \text { How can we convince them that the change is working once it is } \\ \text { needed in the first place? } & \text { underway? } \\ \text { How can we appeal to their intrinsic values (eg, person- } & \text { Is seeing the change in action winning people over and garnering more } \\ \text { centredness, human rights, etc)? } & \text { motivation for the change? }\end{array}$

The social conditions for motivating change

How will you use leadership to create a flow of trust between How can positive peer pressure shape motivation for change? stakeholders?

How can leaders use recognition and reward?
What data can they use to show that change is working?
How can they use negative results to motivate change?
How can they appeal to individual motivations?
How can leaders model enthusiasm and motivation for change?
How will you deal with infectious negativity?
Are there any problems with people being very negative about the
change? Why is this? Is it because the change conflicts with their
own values? Or are they just not receptive to any change?
What impact could this have on how well we implement the
improvement? How will we persevere?

Is there a healthy competitiveness between staff or departments? How will you use champions to convince others?

Can staff be relocated to other areas to lead change and share good practice?

Are there any problems, for example, with unhealthy competition?

\section{How will you harness constructive resistance?}

How can we harness negative views constructively? How will we go about listening to the sceptics? What impact will this have?

\section{The structural conditions for motivating change}

How will you use the physical environment to motivate change?

How can we use physical cues to motivate change? How will these work? What impact will it have?

\section{What financial resource is available?}

Who has control over the finances available-is it locally held or externally controlled? What impact does this have?

Are financial savings reinvested in the service and used to sustain the improvement activity? Or are there no direct financial gains? Either way, how does this affect staff motivation for improvement?

\section{What is the impact of timing?}

How do we create time for improvement? For example, set aside dedicated time? How do we free up time in the schedules of busy practitioners?

How will we think strategically about the timing of introducing the change? For example, wait until we have all resources in place?

How much is planned? How much is opportunism?

\section{How will you use incentives?}

What incentives are in place, for example, accreditation, awards? How will we ensure that our incentives match staff's intrinsic motivations? Is there any disconnect between the incentives (eg, government targets) and what matters to staff in local contexts? How will we deal with this? Could incentives ever have a perverse effect?

How will our methodology support change?

Describe if you will use a structured process, either a local model or an existing approach like Lean or IHI. What impact will this have? For example, does it support motivation for change? Does it create a shared language? Is it a good structure or is it too rigid?

$\mathrm{IHI}$, Institute for Healthcare Improvement.

driven, for example: enabling autonomy by appealing to intrinsic motivations; building competence through turning evidence of change into evidence for change; and fostering relatedness in a flow of trust which spreads and sustains motivation. Presenting evidence for change in a way that is perceived to be valid by those implementing it-as similarly described in Graham's knowledge to action model ${ }^{24}$-increases the likelihood that they will act on it with feelings of autonomy as opposed to obligation. Greenhalgh $e t a \hat{l}$ referred to this as relative advantage, whereby people who perceive tangible advantages for themselves or their work are more likely to embrace extrinsic motivators as their own. The more tailored the knowledge and reasoning provided to staff, the more convincing it is as evidence for change and the more likely they are to internalise it as an extrinsic motivator.

Motivating Change lends strength to the call for improvement scientists to take heed of motivational theory in understanding ownership and self-determination in the change process. $^{25}$ Given that most change in healthcare will likely be externally driven rather than intrinsically derived, it is particularly important to understand the means through which competing motivators can be reconciled. Moreover, it is important to understand how 
motivation for change is garnered and sustained at an individual level, and at a collective level where there can be sufficient momentum to sustain change. ${ }^{13}$ Rogers ${ }^{26}$ concept of diffusion features heavily in improvement science as a way to explain the communication of knowledge across an organisation. Motivating Change demonstrates, however, that it is not simply knowledge that diffuses throughout organisations, but motivations as well. Through a flow of trust, leaders and peers, by externalising their positive motivations for improvement, can convince the collective and generate a shared vision. Conversely, infectious negativity can suppress or hinder motivation for change. While monitoring knowledge use is common-for example, Graham et al $\mathrm{s}^{24}$ knowledge to action model suggests monitoring knowledge use during the sustaining phase in order to identify strategies for maximising sustained practice-there appears to have been no attempt at monitoring individual and collective motivation while implementing and sustaining change. This paper suggests that, in recognising motivation as socially contagious, greater attention should be given to the spread and sustainability of motivations for new innovations, not just the innovations themselves.

\section{Limitations}

The theory of Motivating Change was co-created by three improvement organisations who may not be representative of others engaged in large-scale improvement. Although the organisations recognised the importance of service users in the change process and included this in the theory, their voices did not contribute directly to the theory development and future work could extend to better understanding service users' role. However, it should be noted that, from the perspective of classic grounded theory, the aim of this work was not to generate objective facts, but to develop conceptually general lessons about sustained, large-scale change. Theory is intended to be modified ${ }^{17}$ and this paper provides a foundation for future work where it can be verified and modified to strengthen its usefulness and scope.

\section{CONCLUSION}

Motivating Change conceptualises the psychosocial-structural conditions for large-scale, sustained change. By narrowing the gap between extrinsic and intrinsic motivators, and equipping staff with the capacity and opportunity to act on these motivations, it is possible to create self-improving organisations with a systems structure that welcomes change as a means to improvement. The theory adds to and extends the existing evidence base on how to create largescale sustained change and promotes the shared expertise of those individuals already actively doing improvement work on the ground. Importantly, in highlighting motivational processes as central to the change process, rather than simply one aspect, this paper calls for greater humanising of the improvement process and demonstrates the value in listening to individuals and organisations with successful track records in lasting improvement. It also provides a practical and usable resource in the Motivating Change Framework to facilitate the implementation and evaluation of future large-scale, sustained change.

Twitter To engage with us about this article via twitter: @Jen_Breck @ EBImprovement @NicolaGray001 @toma_madalina84 @maryrenfrew

Acknowledgements The authors thank all the staff represented by the named key authors from the three organisations (Unicef UK, NHS Highland and Healthcare Improvement Scotland) for their time and willingness to co-create theory, and their feedback on drafts of the paper. The authors also thank Karen Ritchie for her comments and Gillian Clark and Fiona Szeller for invaluable administrative support in arranging consultation meetings and facilitating ongoing communication between partner organisations. The authors also thank the team in NHS East Lancashire for sharing their experiences of achieving the BFI Gold Award to help illustrate the concepts within the theory.

Contributors JPB designed the project, led and facilitated the knowledge mobilisation activity, analysed the workshop notes, prepared the complete first draft of the paper and redrafted in response to team input. MJR contributed to design, workshop facilitation, data analysis, commented on drafts and coordinated communication with the partner organisations. MT contributed to workshop facilitation, commented on drafts and contributed to the final writing of the manuscript. NG contributed to workshop facilitation and commented on drafts. SA, CS and RG facilitated partnership working with their organisations, contributed to theory development, commented on drafts and agreed on the final manuscript on behalf of participating members in their organisations.

Funding This work is supported by core funding from the Scottish Improvement Science Collaborating Centre, which is jointly funded by the Scottish Funding Council, Health Foundation, Chief Scientist Office, and NHS Education Scotland. The funding bodies had no role in the design or interpretation of this study or in writing the manuscript.

\section{Competing interests None declared.}

Patient consent for publication Not required.

Provenance and peer review Not commissioned; externally peer reviewed. Data availability statement № additional data are available.

Open access This is an open access article distributed in accordance with the Creative Commons Attribution Non Commercial (CC BY-NC 4.0) license, which permits others to distribute, remix, adapt, build upon this work non-commercially, and license their derivative works on different terms, provided the original work is properly cited, appropriate credit is given, any changes made indicated, and the use is non-commercial. See: http://creativecommons.org/licenses/by-nc/4.0/.

\section{REFERENCES}

1. Dixon-Woods M, Leslie M, Tarrant C, et al. Explaining matching Michigan: an ethnographic study of a patient safety program. Implement Sci 2013;8.

2. Marshall M, Pronovost P, Dixon-Woods M. Promotion of improvement as a science. Lancet 2013;381:419-21.

3. Greenhalgh T, Robert G, Macfarlane F, et al. Diffusion of innovations in service organizations: systematic review and recommendations. Milbank Q 2004;82:581-629.

4. Schouten LMT, Hulscher MEJL, van Everdingen JJE, et al. Evidence for the impact of quality improvement Collaboratives: systematic review. BMJ 2008;336:1491-4.

5. Wutzke S, Benton M, Verma R. Towards the implementation of large scale innovations in complex health care systems: views of managers and frontline personnel. BMC Res Notes 2016;9.

6. Dixon-Woods M, Martin GP. Does quality improvement improve quality? Future Hosp J 2016;3:191-4.

7. Ovretveit J, Staines A. Sustained improvement? Findings from an independent case study of the Jönköping quality program. Qual Manag Health Care 2007;16:68-83.

8. Bray $\mathrm{P}$, Cummings DM, Wolf M, et al. After the Collaborative is over: what sustains quality improvement initiatives in primary care practices? Jt Comm J Qual Patient Saf 2009;35:502-AP3.

9. Wiltsey Stirman S, Kimberly J, Cook N, et al. The sustainability of new programs and innovations: a review of the empirical literature and recommendations for future research. Implementation Sci $2012 ; 7$. 
10. Reed JE, Card AJ. The problem with Plan-Do-Study-Act cycles. BMJ Qual Saf 2016;25:147-52.

11. Powell AE, Rushmer RK, Davies HTO. A systematic narrative review of quality improvement models in health care. NHS Quality Improvement Scotland 2009.

12. Massoud M, Nielsen G, Nolan K, et al. A framework for spread: from local improvements to system-wide change. IHI innovation series white paper Cambridge, MA: Institute for Healthcare Improvement, 2006.

13. May C. Towards a general theory of implementation. Implementation Sci 2013;8.

14. Buchanan D, Fitzgerald L, Ketley $D$, et al. No going back: a review of the literature on sustaining organizational change. Int $J$ Management Reviews 2005;7:189-205.

15. Finlay L. Reflecting on 'Reflective practice'. Practice-based Professional Learning Centre for Excellence in Teaching and Learning paper 52, 2008. Available: http://www.open.ac.uk/opencet// resources/pbpl-resources [Accessed 11 Jun 2017].

16. Martin GP, Weaver S, Currie G, et al. Innovation sustainability in challenging health-care contexts: embedding clinically led change in routine practice. Health Serv Manage Res 2012;25:190-9.

17. Glaser BG, Strauss A. The discovery of ground theory. New York: Alpine, 1967.
18. Little J. Lean change managment: innovative practices for managing organizational change. Happy Melly Press 2014.

19. Langley GJ, Moen RD, Nolan K, et al. The improvement guide: a practical approach to enhancing organizational performance. San Fransico: John Wiley \& Sons, 2009.

20. May CR, Mair F, Finch T, et al. Development of a theory of implementation and integration: normalization process theory. Implementation Sci 2009;4.

21. Maher L, Gustafson D, Evans A. NHS sustainability model NHS Institute for Innovation and Improvement; 2010.

22. Kelly MP, Heath I, Howick J, et al. The importance of values in evidence-based medicine. BMC Med Ethics 2015;16.

23. Ryan RM, Deci EL. Self-determination theory and the facilitation of intrinsic motivation, social development, and well-being. Am Psychol 2000;55:68-78.

24. Graham ID, Logan J, Harrison MB, et al. Lost in knowledge translation: time for a MAP? J Contin Educ Health Prof 2006;26:13-24

25. Smith GP, Williams TM. You can lead a horse to water ... what SelfDetermination theory can contribute to our understanding of clinical policy implementation. J Health Serv Res Policy 2017;22:37-44.

26. Rogers EM. Diffusion of innovations. New York: Simon and Schuster, 1995. 